\title{
Metallic-Pb Nanospheres in Archean Zircon from the Challenger Au Deposit, South Australia
}

\author{
L. Courtney-Davies ${ }^{1}$, C.L. Ciobanu ${ }^{1}$, N.J. CoOK ${ }^{1}$, \\ M.R. VERDUGO-IHL ${ }^{1}$, K. EHRIG $^{2}$, A. SLATTERY ${ }^{3}$
}

${ }^{1}$ The University of Adelaide, S.A. 5005, Australia (liam. courtney-davies@adelaide.edu.au, cristiana.ciobanu@ adelaide.edu.au,nigel.cook@adelaide.edu.au, max.verdugo ihl@adelaide.edu.au, ashley.slattery@adelaide.edu.au) ${ }^{2}$ BHP Olympic Dam, Adelaide, S.A. 5000, Australia (kathy.ehrig@bhp.com)

Metallic- $\mathrm{Pb}$ nanospheres (M-PbNs) are documented within zircon from Archean ultrahigh-temperature metamorphic terranes (UHT; [1,2]). Radiogenic $\mathrm{Pb}$ mobilized from radiation-damaged domains in zircon predating the metamorphic event is trapped as M-PbNs. Dating using nanoSIMS, shows the M-PbNs record the UHT event [3]. Here we report $\mathrm{M}-\mathrm{PbNs}$ in zircon from Challenger, an Archean Au deposit, central Gawler Craton, South Australia. Bonanza ore from the sulfide-poor M1 orebody has been attributed to enrichment of low-Au protore via Au-Bi melts during $\sim 2.4 \mathrm{Ga}$ granulite facies metamorphism at peak conditions of $850^{\circ} \mathrm{C}, 7 \mathrm{kbar}$ [4]. Our study reports on zircon from sulfide-bearing, $\mathrm{Au}-\mathrm{Ag}$-Te ores (M2 orebody) recording a fluid-driven, $300-400{ }^{\circ} \mathrm{C}$ retrograde overprint.

Scanning transmission electron microscopy imaging of $\sim$ $2.6 \mathrm{Ga}$ zircon (Fig. 1A) reveals the presence of M-PbNs with Sc-bearing halos (Fig. 1B, C), and galena nanoparticles (NPs), in unaltered and altered domains, respectively. M-PbNs and $\mathrm{Pb}$-Bi-Te-S-bearing NPs are identified within inherited Archean $(\sim 2.7 \mathrm{Ga})$ zircon with Sc-rich signature from the $\sim 1.6 \mathrm{Ga}$ volcanic-hosted, $\mathrm{Fe}$-oxide $\mathrm{Cu}-\mathrm{Au}$ prospect at Acropolis, Olympic Dam district, eastern Gawler Craton [5]. Preserved $\mathrm{M}-\mathrm{PbNs}$ in zircon from various ore systems can be used, despite later interaction with hydrothermal fluids, to fingerprint inherited lithologies and trace element sources.

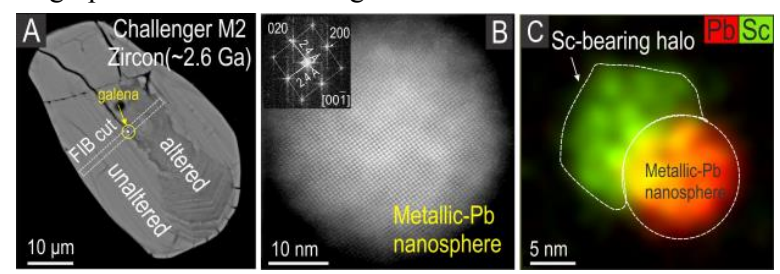

Fig. 1. Metallic $\mathrm{Pb}$ nanosphere, $\sim 30 \mathrm{~nm}$ wide, in Challenger zircon. [1] Kusiak et al. (2015) PNAS, 112, 4958-4963;

[2] Whitehouse et al. (2017) Mineral Petrol, 111, 467-474;

[3] Lyon et al. (2019) Sci Reports, 9, 13702;

[4] Tomkins \& Mavrogenes (2002) Econ Geol, 97, 1249-1271;

[5] Courtney-Davies et al. (2020) Abstract, SEG Conf., Whistler. 